\title{
Transient Stability Improvement of the Power Systems
}

\author{
Zaid H. Al-Tameemi ${ }^{1}$, Hayder H. Enawi ${ }^{2}$, Karrar M. Al-Anbar ${ }^{3}$, Hussam M. Almukhtar ${ }^{4}$ \\ ${ }^{1}$ Departement of Electrical Power Engineering, Al-Furat Al- Awast Technical University, Iraq \\ ${ }^{2}$ Departement of Electrical Engineering, Babylon University, Iraq \\ ${ }^{3}$ Departement of Biomedical, University of Warith Al-Anbiyaa, Iraq \\ ${ }^{4}$ Middle Refineries, Najaf Refinery, Ministry of Oil, Iraq
}

\section{Article Info}

Article history:

Received May 8, 2018

Revised Jul 6, 2018

Accepted Aug 23, 2018

\section{Keywords:}

7-Machine CIGRE System

Stability enhancement methods

Transient stability

\begin{abstract}
During the last few decades, electrical power demand enlarged significantly whereas power production and transmission expansions has been brutally restricted as a result of restricted resources as well as ecological constrains. Consequently, many transmission lines have been profoundly loading so the stability of power system became as Limiting factor for transferring electrical power. So, maintaining a secure and stable operation of the electric power networks is deemed an imporatant and challenge issue.transient stability of a power system has been gained a considerable attention from researchers dute to it importance. Therefore, this paper sheds light on A substantial number of the adopted techniques, including an inclease in inertia constant of generator, shunt capacitor, reduction reactance of the transmission line to acheive this purpose. A 7-Machine CIGRE system has been considered a case study. Matlab package has been employed to implement this study. The simulation results show that the transient stability of the repective system enhanced considerably with these technques.
\end{abstract}

Copyright () 2018 Institute of Advanced Engineering and Science. All rights reserved.

\section{Corresponding Author:}

Zaid H. Al-Tameemi,

Departement of Electrical Power Engineering,

Al-Furat Al- Awast Technical University,

Iraq.

Email: zaid_altameemi@tcm.edu.iq

\section{INTRODUCTION}

Currently, electricity demand has significantly increased and a current electrical power system becomes a complicated network of the transmissions lines which interconnect the power staions to the main points of loads in the whole power system to provide consumers with the required power. The complex power networks cause some technical issues such as stability problem [1]. Power system stability of current big interrelated systems is considered a key issue for secure system operation. It is worth mentioning that current major shutdowns across the world prone to system instability, even in advanced and protected systems, elucidate the difficulties facing stable operation of electrical power systems [1-3]. In this regard, power system stability can be defined as the ability of system to return to normal operation condition after being exposed to some kinds of interruptions [4]. Power stability can be divided into several categories such as frequency voltage, rotor angle stability and voltage stability [5,6]. Many researches have been done to assess stability of the power system and then enhance it, especially transient stability whicht is deemed as one of the signicafint aspects that have to be taken in consideration in the recent power systems. Several techniques have been proposed to enhance the transient stability of the modern power systems, including Flexible AC Transimission systems (FACTS), and distributed generation units (DG ) [7].

This paper presents the different technique of the enhancement of transient stability of the abovementioned power system based on using shunt capacitor, an increase in inertia constant of generator, and decrasing the transmission line reactance as explained in the second part. The simulation code has been 
implemented in the Matlab enivorment. it has been tested on the single line diagram and data of $225-\mathrm{kV}$, 7-machine CIGRE system (in pu on a 100 MVA base).

\section{STABILITY ENHANCEMENT TECHNIQUES}

Transient stability improvement can be achived by adopting one of the following method:

\subsection{Inertia Constant of Generator}

Inertia of machine can be defined as a kinetic energy that stored in moving parts of the machines at the synchronous speed per-unit MVA machine rating. It represents a rate of its decelarion or accerlartion which indicates rate of change in the rotor angle. It is worth mentioning that the higher the inertia, the slower the rate of change in angle. This decreases the kinetic energy gained during fault; so accelerating area is decreased [8].

\subsection{Shunt Capacitor}

Connect capacitors are connected in more than one bus to supply specific amount of reactive power. This is because the main reason of occuring disturbances is the lack of reactive power therby injecting reactive power will improve the stability of the system as well as it increase the load carrying capbility of the transimission line [9].

\subsection{Reduction of the Transmision Line Reactance}

This technique invloves reducing the reactance of the transmission lines and that plays an important role in improving the power transferred and the stability of the system because the transferred apperant power proretionals inversly with the reactance according to the equation below:

$$
P=\frac{V 1 x V 2}{X} \sin \delta
$$

\section{SYSTEM STRUCTURE}

The single line diagram and data of 225-kV, 7-machine CIGRE system (in pu on a 100 MVA base) are given in the appendix. this system consists of 10 buses which include one slag bus, six PV buses, and three load buses, single line diagram and data of 225-kV, 7-machine CIGRE System as shown in Figure 1.

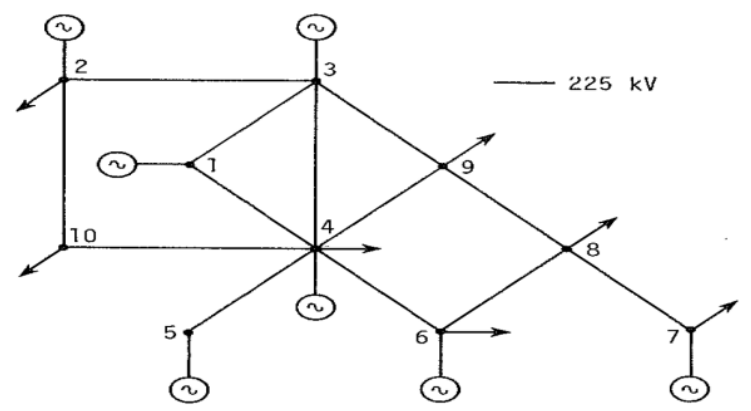

Figure 1. Single line diagram and data of 225-kV, 7-machine CIGRE System

\section{SIMULATION RESULTS}

In this section, different techniques are considered to evaluate the impact of eachmethod on the transient stability of a 7-machine CIGRE system.

Case 1: Normal situation

A 7-machine CIGRE System has been tested at the normal situation to evaluate transient stability. In this situation, it has been noticed that the system maintains the stability as long the circuit breaker working on the removal of the damaged bus from the system as soon as possible. This has been observed by increasing the clearing time from $0.05 \mathrm{~s}$ to 0.39115 that represents critical clearing time of the fault. During the bounded period, the system keeps its stability as shown in the Figure 2: 


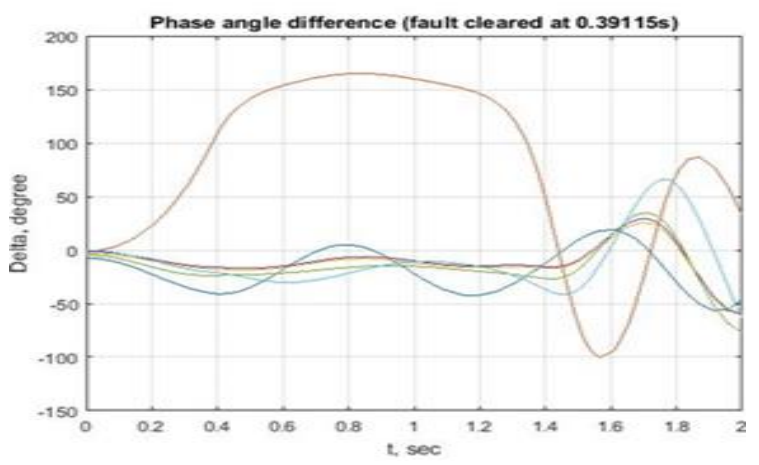

Figure 2. Swing curves for a stable situation

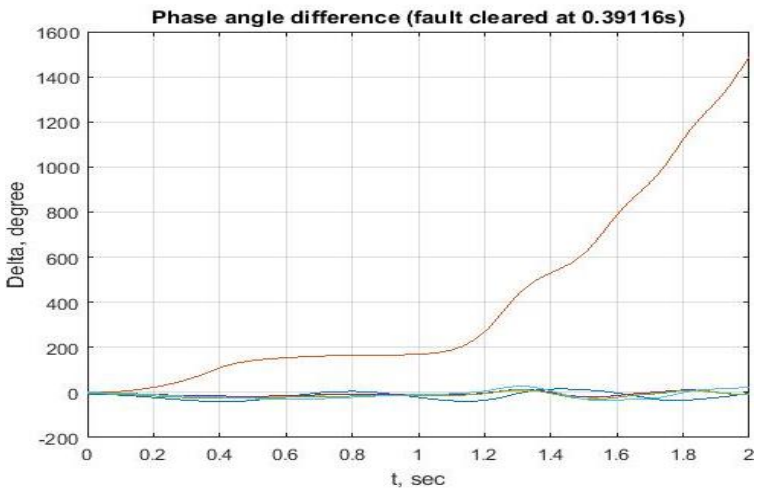

Figure 3. Swing curves for an unstable situation

From the Figure 3, it has been observed that $0.39115 \mathrm{~s}$ is regarded as critical time of system and 0.39116 is unstable time. In the second part, some techniques will be applied to increase the clearing time to Long as possible to improve the stability of the system.

Case2: an increase in inertia constant of generator $(\mathrm{H})$

This method is classified as one of the main techniques for improving the transient stability of the power systems. In fact, when the inertia becomes higher that makes the rate of change in angle slower. The gain of kinetic energy depends directly on angle rate change. Therefore, when the rate decreases, the gained kinetic energy during fault will also decease then accelerating area reduces so the system stability remains with the desirable level [10]. During our practical, we found that our original system stays stable until clearing time equal 0.39115 second then it became unstable at $t c l=0.39116$ second without changing or adding anything as shown the photos in Figure 4.

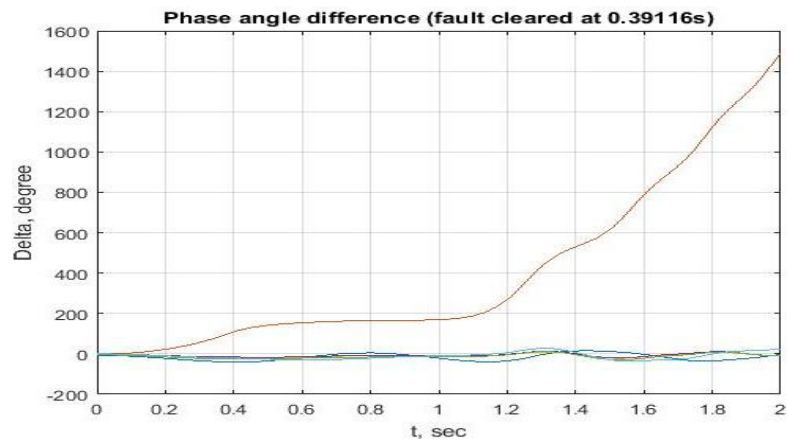

Figure 4. Swing curves for an unstable situation 
Now, we multiplied the inertia of all generators by two and check again the tc for the system. We found that the system stayed stable in this situation until tcl $=0.5531$ second then it became unstable at tcl $=0.5532$ second and the Figure 5-6.

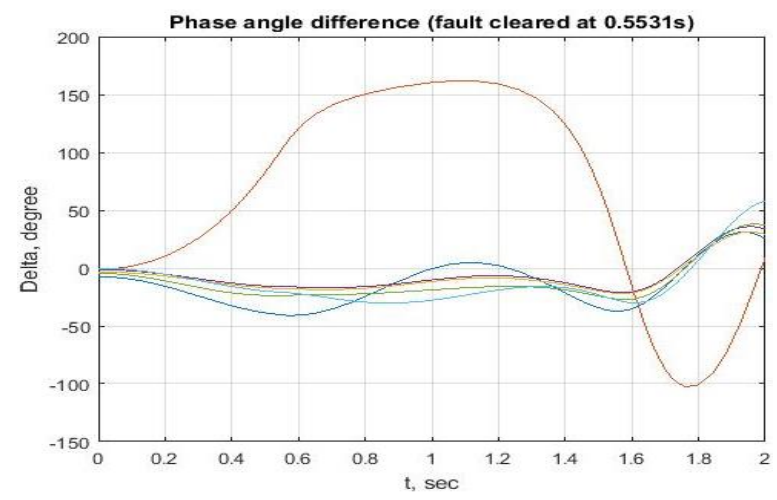

Figure 5. Swing curves for an unstable situation

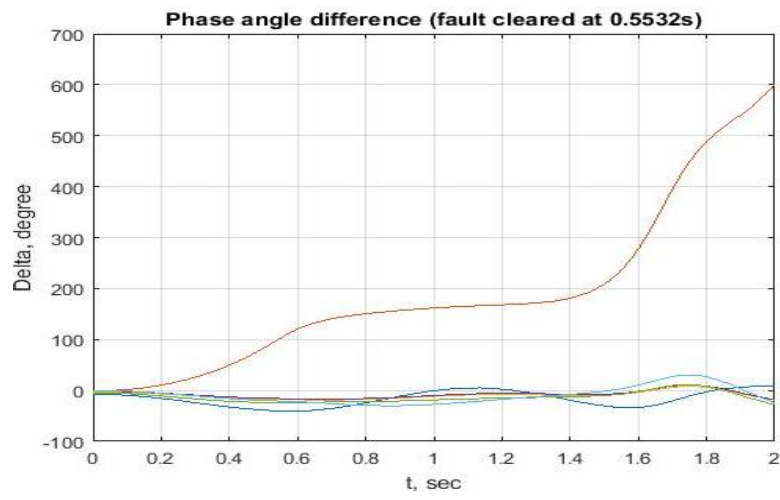

Figure 6. Swing curves for an unstable situation

Moreover, we multiblied the inertia of the generaters by three and repeat the above steps. It is observed that the the system remains stable untill $\mathrm{tc}=0.6774$ second then be unstable when $\mathrm{tc}=0.6775$ second as shown in the Figure 7-8.

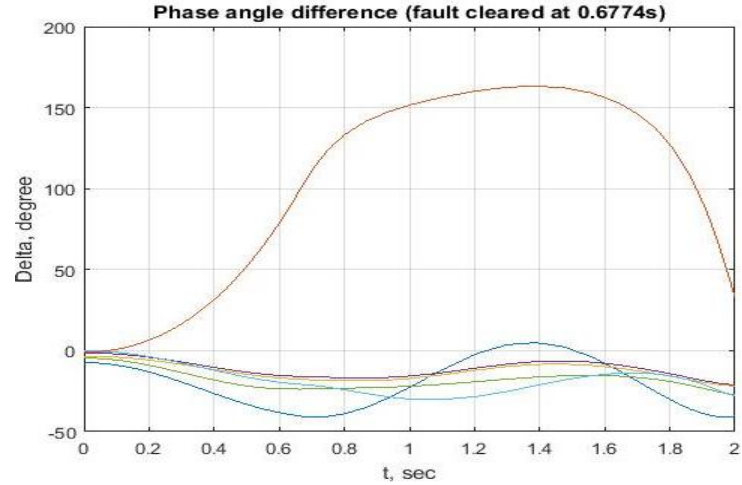

Figure 7. Swing curves for an stable situation 


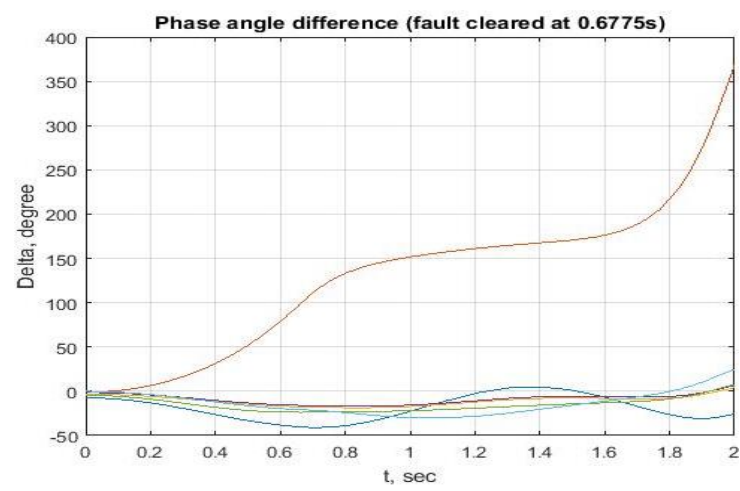

Figure 8. Swing curves for an unstable situation

Case3: Connecting Shunt Capacitor

In this case, shunt capcitor is connected in two different places to evalute its impact on the system.Firstly, two capacitors are connected to the system one on the bus 8 with 80 Mvar and the other is 60 Mvar on the bus 10 . In this case, the system remained stable untill tc $=0.39319$ second and be unstable attc $=0.3932$ second as shown in the Figure 9-10.

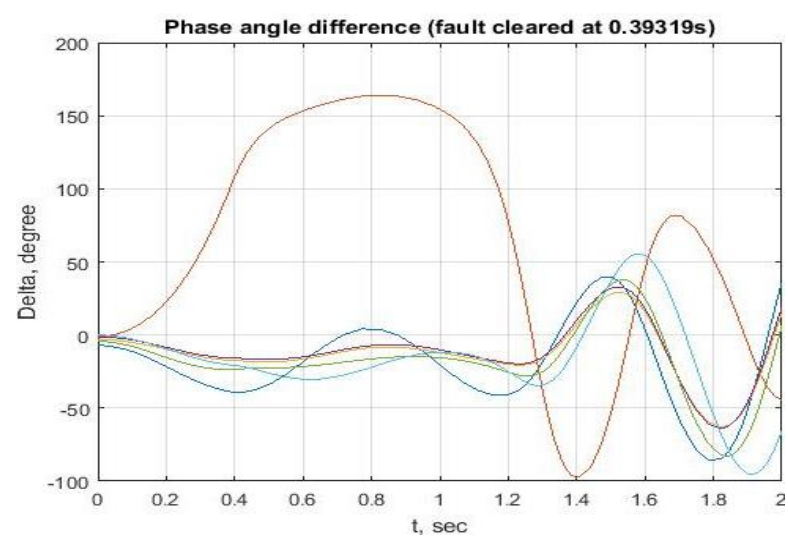

Figure 9. Swing curves for a stable situation

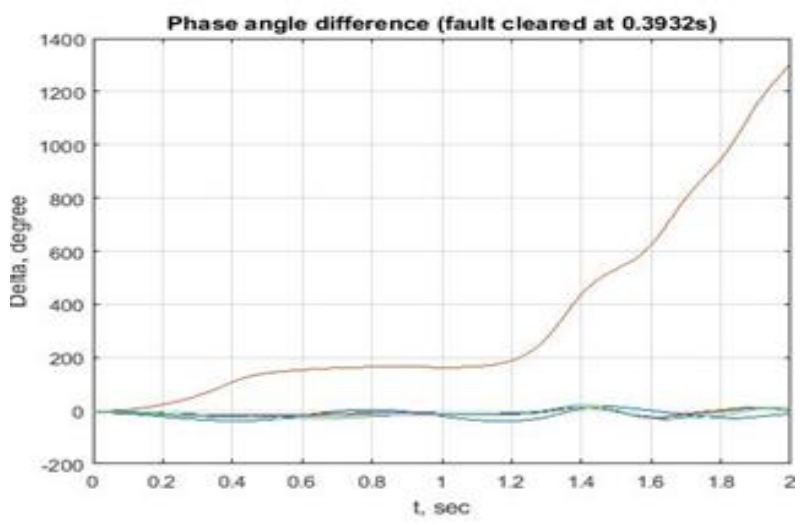

Figure 10. Swing curves for an unstable situation 
Secondly, the amplitude of the injected reactive power had be increased from 80 Mvar to 100 Mvar on bus 8 and from 60 Mvar to 80 Mvar on bus 10, then the system stayed stable untill tc $=0.39387$ second and became unstable at $t c=0.39388$ second as shown in Figure 11-12.

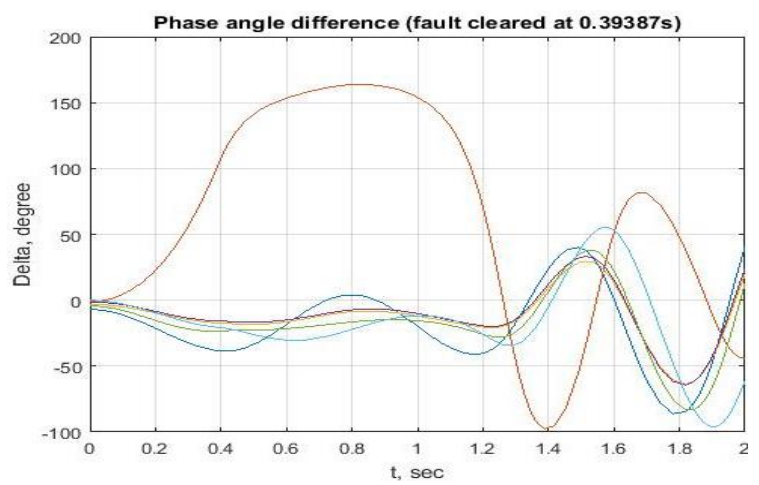

Figure 11. Swing curves for a stable situation

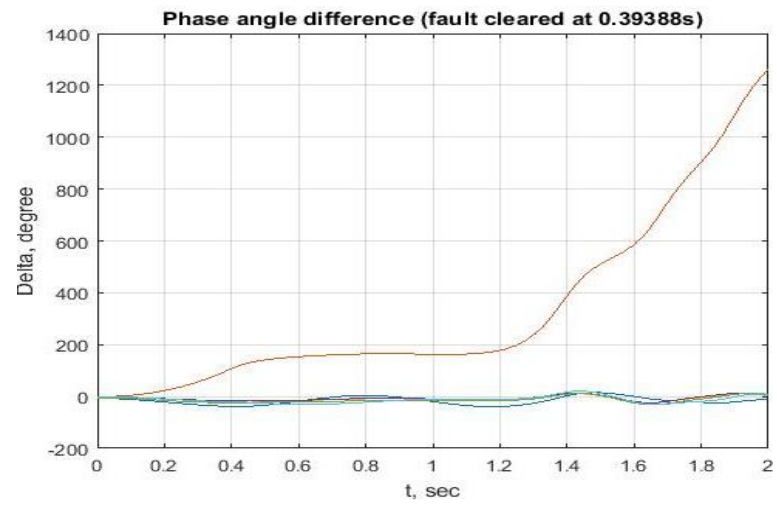

Figure 12. Swing curves for an unstable situation

Case4: Reduction of the transmission line reactance

In this case, two different scinarios has been done to assess the influence of reactance redction on the system stablity. The first case involves reducing the reactances between bus 2 to 10 and bus 1 to 4 to the half of their values. Then, the tcl increases to 0.39326 second and the system is stable after that it became unstable at tc $=0.39327$ second as described in the Figures 13-14.

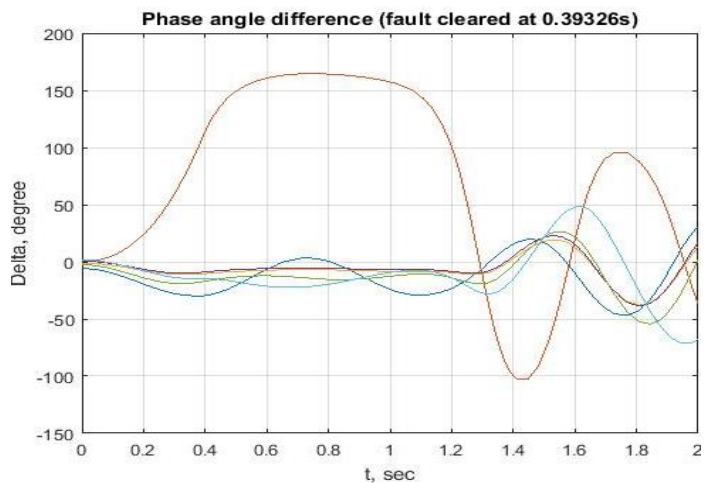

Figure 13. Swing curves for a stable situation 


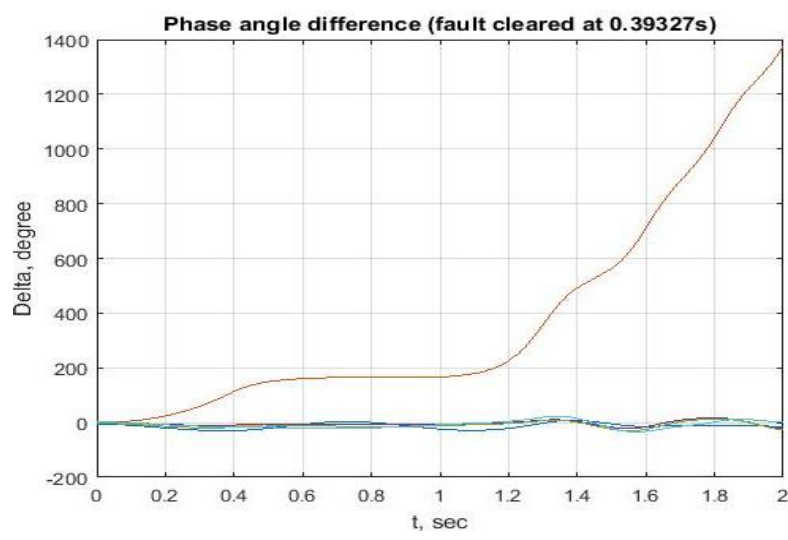

Figure 14. Swing curves for an unstable situation

In the second case, the same reactance which was used in the first case are used here a but multipiled by 0.25 inseated of 0.5 . it shows that the system is able to remain stable up to tc $=0.39642$ second and then it will be unstable at tc $=0.39643$ second as shown in Figure 15-16.

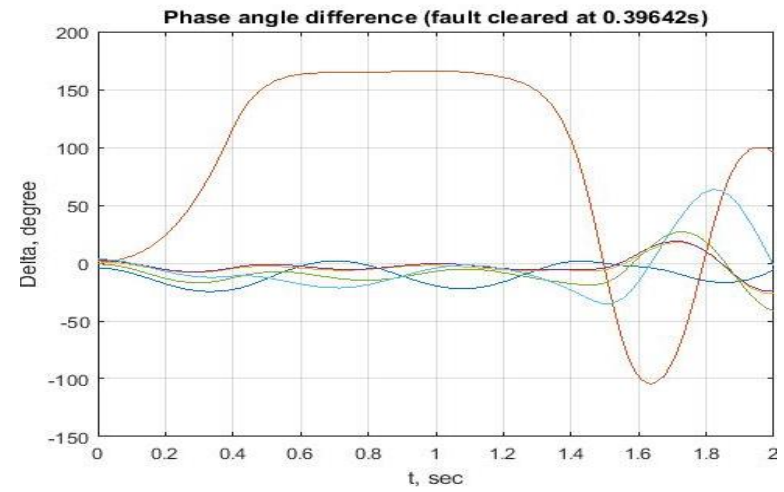

Figure 15. Swing curves for a stable situation

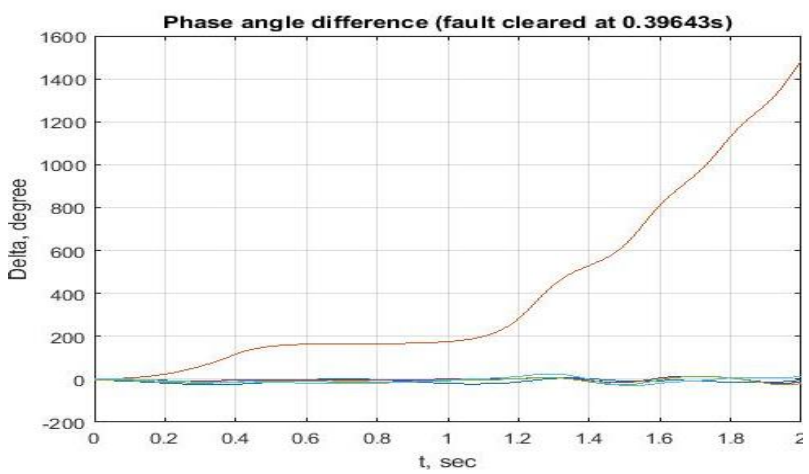

Figure 16. Swing curves for an unstable situation

From these three method, it can be seen that the first method (by increasing the inertia of the generators) is much better than the other two because it increases clearing time very high as compard with other two stratgies. 


\section{CONCLUSION}

This paper has been dedicated to assess the transient stability of 7-Machine system. It shows that the system retains its stability as long the circuit breaker working on the exclusion of the damaged bus from the respective system as soon as possible. In order to comprehend this case, A 7-Machine system has been taken as a sample. It has been found that system loses its stability at $0.39116 \mathrm{~s}$. Then three techniques have been used to improve stability effectively and proves that practically. The adopted strategies includes increasing generator inertia constant, connecting shunt capacitor, and decreasing the reactance of the transmission lines. It should be clear that increasing generator inertia constant is found the best way to achieve this purpose where the clear time goes up to 0.6774 s.

\section{REFERENCES}

[1] Azim, M.I., Wahed, M.A. and Chowdhury, M.A.H., 2015. Power Flow and Transient Stability Improvement by Static Synchronous Series Compensator. Indonesian Journal of Electrical Engineering and Computer Science, 15(1), pp.71-77.

[2] Thuy, N.T.D. and Ngoat, T.T., 2013. Assessment study of STATCOM's effectiveness in improving transient stability for power system. Indonesian Journal of Electrical Engineering and Computer Science, 11(10), pp.6095-6104.

[3] Kimbark, E. W. (1995). Power system stability (Vol. 1). John Wiley \& Sons.

[4] Kundur, P, Paserba, J, Ajjarapu, V, Andersson, G, Bose, A, Canizares, C, et al 2004, 'Definition and classification of power system stability IEEE/CIGRE joint task force on stability terms and definitions', Power Systems, IEEE Transactions on, vol. 19, no. 3, pp. 1387-1401.

[5] Kundur, P. (1994). Power system stability and control (Vol. 7). N. J. Balu, \& M. G. Lauby (Eds.). New York: McGraw-hill.

[6] Sivachandran, P, Hariharan, T \& Pushpavathy, R 2015, 'Improvement of power system stability using D-facts controllers: A review', ARPN Journal of Engineering and Applied Sciences, vol. 10, no. 2, pp. 933-939.

[7] [7] Saric, M., 2017. Generator dynamic response analysis and improvement following distribution network disturbance. Indonesian Journal of Electrical Engineering and Computer Science, 7(2), pp.356-363.

[8] Mbangula, K.N.I., Davidson, I.E. and Tiako, R., 2016. Improving Power System Stability of South Africa's HVAC Network Using Strategic Placement of HVDC Links. CIGRE Science \& Engineering Journal (CSE), 5, pp.71-78.

[9] Abdelhay, A.S., Mohamed, D. and Hussien, D., 1994. Shunt Capacitor Effect on Electrical Distribution System Reliability'. IEEE Transactions On Reliabilty, 43(1).

[10] Jha, B.K., Gupta, R.P. and Prasad, U., 2014. Combined Operation of SVC, PSS and Increasing Inertia of Machine for Power System Transient Stability Enhancement. International Journal of Applied Power Engineering (IJAPE), 3(1), pp.15-22.

\section{APPENDX}

Bus Data of the 7-machine CIGRE System

\begin{tabular}{|c|c|c|c|c|c|c|}
\hline Bus\# & $V(p u)$ & $P_{\text {Load }}(M W)$ & $Q_{\text {Lood }}(M V A r)$ & $P_{\text {gen }}(M W)$ & $Q_{\text {min }}$ (MVAr) & $Q_{\text {max }}(M V A r)$ \\
\hline 1 & 1.060 & & & $--S w i n g--$ & -200 & 200 \\
\hline 2 & 1.000 & 200 & 120 & 120 & -200 & 200 \\
\hline 3 & 1.040 & & & 256 & -200 & 200 \\
\hline 4 & 1.015 & 650 & 405 & 300 & -200 & 200 \\
\hline 5 & 1.055 & & & 230 & -200 & 200 \\
\hline 6 & 1.020 & 80 & 30 & 160 & -200 & 200 \\
\hline 7 & 1.010 & 90 & 40 & 175 & -200 & 200 \\
\hline 8 & & 100 & 50 & & & \\
\hline 9 & & 230 & 140 & & & \\
\hline 10 & & 90 & 45 & & & \\
\hline
\end{tabular}

Generator Data of the 7-machine CIGRE System

\begin{tabular}{|c|c|c|c|}
\hline Gen \# & Resistance $(\mathrm{pu})$ & $\begin{array}{c}\text { Transient } \\
\text { Reactance }(\mathrm{pu})\end{array}$ & $\begin{array}{c}\text { Inertia } \\
\text { Constant }(\mathrm{H})\end{array}$ \\
\hline 1 & 0 & 0.074 & 11.35 \\
\hline 2 & 0 & 0.118 & 7.75 \\
\hline 3 & 0 & 0.062 & 14.31 \\
\hline 4 & 0 & 0.049 & 17.98 \\
\hline 5 & 0 & 0.074 & 11.35 \\
\hline 6 & 0 & 0.071 & 12.76 \\
\hline 7 & 0 & 0.087 & 10.71 \\
\hline
\end{tabular}

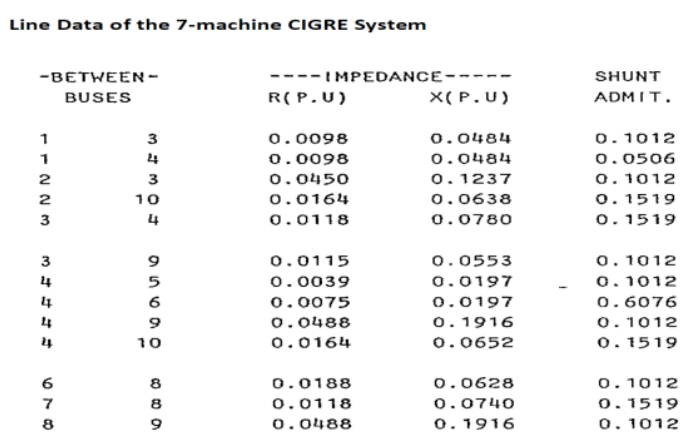

